\title{
Crise do capitalismo e a necessária mutação de paradigmas nas relações justrabalhistas
}

\section{Crisis of capitalism and the necessary changes of paradigm in labor relations}

\author{
Maria Lírida Calou de Araújo e Mendonça* \\ Saulo Nunes de Carvalho Almeida**
}

\section{Resumo}

O presente estudo defende a necessidade de maiores reflexões acerca da busca pela harmonia entre o direito à livre iniciativa e à valorização do trabalho humano, analisando como esses valores fundamentais devem coexistir em um Estado pós-crise do capitalismo. O texto defende um Estado norteado pela efetivação dos princípios da ordem econômica, reconhecendo se tratar de um objetivo que apenas poderá ser alcançado por meio de uma nova interpretação do conteúdo jurídico da livre iniciativa, harmônica com os princípios da valorização do trabalho humano e da justiça social.

Palavras-chave: Livre mercado. Valorização do trabalho humano. Crise do capitalismo.

\section{Abstract}

The present paper defends the need to think deeper about the quest for the harmony between the right to free enterprise and the exploitation of human labor, analyzing how these values must coexist in a State post-capitalism crisis.

* Doutora em Direito pela Universidade Federal de Pernambuco. Mestre em Direito pela Universidade Federal do Ceará. Professora do Programa de Pós-Graduação em Direito Constitucional da Universidade de Fortaleza. Coordenadora do Curso de Direito da Faculdade Católica Rainha do Sertão. Fortaleza - CE - Brasil. Email:

** Doutorando e mestre em Direito Constitucional pela Universidade de Fortaleza. Especialista em Direito do Trabalho, Tributário e Previdenciário pela Faculdade Ateneu. Professor de Direito do Trabalho e Direito Tributário. Advogado. Fortaleza - CE - Brasil. Email: saulo@unifor.br 
It will be defended a vision of a State guided by the principles of a effective Economic Order, where these do not correspond to simple utopia, which can only be achieved through a new interpretation of the legal content and amplitude of free enterprise, allowing yourself to be achieved greater effectiveness of the principles of human labor and social justice.

Keywords: Free market. Enhacement of human labor. Capitalism crisis.

\section{Introdução}

O impacto do capitalismo global sobre as nações emergentes tem sido o de estabelecer uma marcha rumo à precarização do emprego, através dos fenômenos de flexibilização e desregulamentação laboral, como forma de atrair as empresas multinacionais que, supostamente, permitiriam um maior combate ao desemprego e à escassez de postos de trabalho. Esses fenômenos ocorreram especialmente em nações não possuidoras de maior desenvolvimento tecnológico e que, para se tornarem atrativas o suficiente para as empresas globais, oferecem mão de obra para contratação com menos encargos do que as nações desenvolvidas, sendo essa a única forma de serem competitivas.

Essa visão corresponde a uma das grandes questões a serem enfrentadas em um futuro próximo: seriam esses reflexos integrantes da própria estrutura predatória do sistema capitalista atual ou se trata apenas de um mito, uma profecia oriunda das corporações globais para alcançarem seus objetivos de redução de custos?

O presente estudo apresentará maiores reflexões acerca desse relevante questionamento, estabelecendo uma ligação entre a crise do capitalismo e a necessária mudança de paradigmas das relações jurídico-laborais como requisitos essenciais para a reconstrução dos princípios de justiça social e existência digna da classe trabalhadora.

Resta evidente que a sistemática de ordem econômica estabelecida pela Constituição Federal de 1988 não foi alcançada, 
fazendo-se necessária a busca por novas diretrizes normativas ${ }^{1}$ que reconduzam as relações empresariais rumo aos valores constitucionais do Estado Democrático de Direito, que apenas poderá ser alcançado por um processo de desconstrução dos velhos paradigmas da relação capital $x$ trabalho e proposição de novos, partindo da premissa básica do direito de livre iniciativa da empresa exercida harmonicamente com a valorização do trabalho humano.

\section{O emblemático equilíbrio entre lucratividade e a valorização do trabalho humano}

O legislador constituinte, através do artigo 170 da Constituição Federal, ao estabelecer o amplo direito à liberdade de iniciativa, não o fez de forma desconexa dos demais valores estruturantes de uma democracia. A livre iniciativa não pode ser vista pelo conceito predominante em regimes capitalistas de absolutismo ${ }^{2}$, devendo ser interpretada como corolário da valorização constitucional dada ao trabalho humano, responsável por conferir conteúdo social à atividade econômica. Todo o modelo de produção e organização social deverá ser temperado e presidido pelos parâmetros de um trabalho digno e justo, entendido como um dos fundamentos do Estado Democrático de Direito.

Sarlet (2012, p. 563) explica: "a exemplo das demais normas de direitos fundamentais, as normas consagradoras de direitos sociais possuem aplicabilidade direta, ainda que o alcance de sua eficácia deva ser avaliado sempre no contexto de cada direito social e em harmonia com outros direitos fundamentais (sociais ou não), princípios e mesmo interesses públicos e privados".

2 Afinal, não se pode negligenciar todo o complexo processo histórico que culminaria na ruptura do paradigma constitucional do Estado liberal e a insurgência de um novo modelo, de natureza social. O fundamento dessa alteração de paradigmas repousou na identificação de uma nova (e maior) ameaça à exploração do homem, cometida não mais exclusivamente pelo Estado (a qual séculos atrás culminaria na implementação do Estado Liberal), e sim pelo próprio homem. Adentra-se em um novo momento da história, em que a satisfação da condição humana passa a necessitar de novas exigências sociais (demandas que viriam a acarretar na construção de uma gama de novos direitos, tradicionalmente conhecidos como de $2^{\mathrm{a}}$ dimensão) que apenas podem ser alcançadas por meio de uma ruptura com o antigo paradigma liberal e a realização de uma releitura das funções do Estado, em busca de sua ampliação. Essa redefinição da função estatal frente à sociedade resultaria no Estado do bem-estar-social, atribuindo-lhe novas obrigações, de natureza econômica e social. 
Uma das ideias centrais da Constituição de 1988 foi reconhecer plenamente, por meio da principiologia estabelecida no capítulo da ordem econômica, a valorização do trabalho humano como condição essencial à dignidade do homem, atuando como um princípio geral norteador do Direito, a que a atividade econômica não se encontra imune. Nesse sentido, a ordem econômica vigente estabelece um papel mais ativo para o Estado, cabendo a ele assegurar os primados de uma livre iniciativa orientada pelo prestígio ao trabalho humano, estabelecendo limites interventivos e cogentes sobre a função empresarial, que deverá ser exercida de modo harmônico com os direitos sociais da classe trabalhadora. Ficará a cargo do Estado essa intervenção de balanceamento, buscando-se formas de amenização da tensão social existente entre a livre iniciativa privada e a justiça social.

O capitalismo ultraliberal, que tomou fôlego com a doutrina do Estado liberal e se enraizou no sistema econômico de diversos países, encontra-se em um momento de severa crise global. Esse modelo de capitalismo, pautado nas regras de um livre mercado e de acirrada competitividade entre as empresas, desconstrói noções básicas de garantias sociais e igualdade, comprometendo, nos mais distintos aspectos, as condições de vida da classe trabalhadora menos favorecida, que, explorada pelo capital como fator de produção, não consegue alcançar condições de vida digna, produzindo uma classe de subproletariados $^{3}$. Criticando as consequências nefastas da doutrina clássica de livre iniciativa da ordem econômica norte-americana, Baran e Sweezy (1966, p. 335) assim se pronunciam:

A realidade social é, portanto, concebida em termos superados, confusos e fetichistas. Incapazes de justificar

\footnotetext{
Ao analisar a crise econômica experimentada pelo Brasil nos anos 1960 e seus efeitos sobre o desenvolvimento, equidade e justiça social, Cardoso (1985, p. 77) explana a existência de um quadro comum ao capitalismo local, de crescimento econômico da empresa e diminuição dos direitos sociais, como o aumento da pobreza: "Ao invés de crescimento, estagnação. Ao invés de maior igualdade, os coeficientes Gini de distribuição da renda passaram a mostrar, depois da década de 60 , concentração de riqueza e aumento relativo da miséria. Ao invés de mais fraternidade, coerção."
} 
uma ordem social irracional e inumana, e incapazes de responder às perguntas cada vez mais prementes que ela suscita, a ideologia burguesa se apega a conceitos anacrônicos e moribundos.

A apologia ao neoliberalismo e à globalização da economia como um caminho natural da evolução da humanidade, sem alternativas quanto à adoção de seus princípios e dogmas, começa a ser colocada sob suspeita, tendo em vista a desintegração social dela oriunda ${ }^{4}$.

É notável que, apesar dos princípios sociais da ordem econômica terem tido seu lugar assegurado no texto constitucional, ainda continuam a ser amplamente desrespeitados, tanto no que diz respeito à função do Estado de harmonizador da liberdade de mercado com o prestígio de um trabalho humano digno como pelo sistema econômico do mundo corporativo e seus valores estruturantes centralizados em um desejo de lucratividade a todo custo, responsável por abalar as estruturas constitucionais que deveriam nortear todas as atividades econômicas.

A maior prova dessa postura empresarial de otimização no corte de custos corresponde ao fato de que, no Brasil, 15,3 milhões de trabalhadores (equivalentes a $28,2 \%$ do total de empregados) se encontram na informalidade ${ }^{5}$, sem terem a carteira de trabalho assinada ${ }^{6}$. Esse dado alarmante se justifica por uma ausência de fiscalização e punição efetiva por parte do Estado e pelo fato de que diversas empresas têm utilizado essa "técnica" como estratégia para diminuição de gastos, alcançando maior competitividade em relação às concorrentes.

$4 \quad$ Keller (2001, p. 71) esclarece: "Fala-se muito em 'crise do Estado Social', que atinge os direitos sociais, para cuja realização se exige a prestação efetiva dos serviços que ao Estado compete. Entretanto, por falta de garantias jurídicas apropriadas, termina ficando ao alvedrio dos detentores do Poder [...]. Constata-se uma carência de mecanismos de regulação."

5 Dados do PNAD e IBGE de 2009. Disponível em: <http://www.ibge.gov.br>. Acesso em: 04 maio 2012.

6 Isso os exclui da possibilidade de usufruir de diversos benefícios do INSS, como auxílio-doença, licença-maternidade, seguro-desemprego, comprovação do tempo de serviço para fins de aposentadoria etc. 
Conforme será explorado ao longo do estudo proposto, os exemplos desse processo de downsizing, destinados à redução de custos da mão de obra, não se limitam ao exposto anteriormente. Outros fenômenos desse mercado globalizado, que conecta o mundo corporativo, também se manifestam na utilização abusiva da terceirização de trabalhadores, no dumping social, na dispensa coletiva, na flexibilização dos direitos trabalhistas, no elevado número de acidentes de trabalho, entre outras formas de precarização das conquistas sociais, demonstrando o atual estado de desvalorização dos princípios que regem a ordem econômica nacional, em que eles experimentam uma fase de ausência de efetividade, vítimas de uma infindável sucessão de violações.

Deve-se romper com a visão predominante de que os princípios da ordem econômica correspondem a uma utopia e são possuidores de um conteúdo esvaziado de qualquer sentido mais amplo. Defende-se a busca por uma nova postura, que permita aos princípios da valorização do trabalho humano e da justiça social alcançarem status de verdadeiras normas jurídicas, portadoras de elevado teor normativo.

Todavia, não se pode acreditar que essa necessária mutação da conjuntura econômica ocorrerá naturalmente, oriunda de uma alteração virtuosa da consciência dominante das bases do sistema capitalista, ou por pura bondade do empresariado, não se devendo ignorar o fato de que este tende a atuar pautado nos princípios da racionalidade, respondendo aos incentivos que se encontram à sua volta, bem como aos custos de transação das operações de mercado passíveis de realização. Logo, em um sistema no qual os riscos do descumprimento de normas apresentam benefícios econômicos mais elevados do que a sua rigorosa observância, o seu inadimplemento comumente será a postura adotada?.

A doutrina socialista moderna mais otimista, abastecida pelas consequências sociais da crise atual, tem defendido que, com o

Para maiores reflexões, analisar a Teoria do Inadimplemento Eficiente (Efficient Breach Theory), responsável por estudar os custos de transação nas mais distintas operações econômicas. 
término da crise, será alcançada uma redenção através da extinção do capitalismo. Não acreditamos que isso correrá. As crises do capitalismo são cíclicas, oriundas de sua instabilidade natural, e o que virá com o seu fim deverá ser a sua transformação, sua evolução, um modelo condizente com alguns anseios sociais, mas não todos.

Ao contrário de posicionamentos socialistas mais extremos, que têm se alastrado e alcançado um maior número de seguidores, muito graças à difusão de movimentos como o "occupy", iniciados em 2011, não será defendido aqui o fim do capitalismo. Ele não será apresentado como modelo de difusão da miséria, pobreza e exclusão social; nem será estudado como algo maligno, aniquilador de direitos sociais ${ }^{9}$. capitalismo será analisado como uma expressão natural das sociedades modernas que desenvolve novas bases, novos valores, acarretando no seu fortalecimento. O Brasil, tal qual o restante do mundo, encontra-se nesse momento de transição de sistemas, em que se levantam vozes questionadoras indagando se seria possível o alcance de uma sociedade pautada na combinação balanceada entre avanços econômicos e progresso social.

A realidade é que o simples declínio do capitalismo não acarretará, por si só, em um novo modelo de Estado, pautado nos ideais

8 Aponta Peschanski (2012, p.27): “os 'ocupas' põem na pauta política justamente a discussão de alternativas aos regimes econômicos desiguais e à experimentação do igualitarismo democrático radical. E, com exceção dos ricos, que de fato saem perdendo, participar dessa discussão é de interesse de toda a população".

9 Com propriedade, Castells (2000, p.95) explica: "os movimentos sociais podem ser conservadores, revolucionários, ambas as coisas, ou nenhuma delas. Afinal, concluímos [...] que não existe uma direção predeterminada no fenômeno da evolução social, e que o único sentido da história é a história que nos faz sentido. Portanto, do ponto de vista analítico, não há movimento sociais 'bons' ou 'maus'. Todos eles são sintomas de nossas sociedades, e todos causam impacto nas estruturas sociais, em diferentes graus de intensidade e resultados distintos que devem ser determinados por meio de pesquisas". Oportunas, também, as palavras de Morin (1986, p. 64) ao questionar o perigo das ilusões que catapultam "movimentos" e "revoluções" do social sobre o capital, explanando que, no século passado, "as Revoluções foram à deriva, desviaram-se em sentido contrário, tornaram-se reacionárias. Vemos a ideia de Revolução levar ao terrorismo alucinando. Daqui em diante, temos de saber que toda a revolução feita sob a bandeira do marxismo-leninismo pelo partido-do-proletariado leva a uma dominação e exploração. Devemos saber que uma libertação pode conduzir a uma servidão pior do que aquela que destruiu, se for orientada por uma organização que subjuga". 
de solidariedade social. Essa meta apenas poderá ser alcançada por meio de um processo de revolução social, rompendo-se com os valores estruturantes de um sistema capitalista ultraliberal ${ }^{10}$ e repensando as matrizes clássicas das relações jurídico-laborais ${ }^{11}$, permitindo, assim, um equilíbrio harmônico entre livre iniciativa, justiça social e valorização do trabalho humano, conforme já alertava Habermas (1980, p. 63) ao afirmar que "a tendência à crise econômica se afirmará, também, com uma crise social e levará a lutas políticas”.

\section{A dogmática jurídica tradicional do princípio da liberdade de iniciativa econômica e a sua necessária reconstrução}

A Constituição de 1988 estabelece como um dos fundamentos da República Federativa do Brasil e um dos princípios da ordem econômica a livre iniciativa. Trata-se de uma relevante projeção dos direitos de liberdade individual, correspondendo ao direito de todo homem de, por sua conta e risco, adentrar no mercado de produção. Segundo Silva (2003, p. 65):

[...] liberdade seria a possibilidade de escolher seus próprios caminhos profissionais ou suas próprias atividades econômicas, com ausência de coação ou interferência do Estado; seria a possibilidade de iniciativa individual, sem interferência do Estado no jogo do mercado, como meio de se atingir o máximo de eficiência na produção e de justiça na repartição do produto.

Habermas (1980, p. 47) alerta que "a suplementação e parcial substituição do mecanismo de mercado pela intervenção estatal marca o fim do capitalismo liberal".

11 Matrizes como aquelas apontadas por Marx (2006, p. 114), que reconhece a propriedade como princípio central do capitalismo, difundindo seus reflexos inclusive sobre o processo evolucionário da divisão do trabalho: "A divisão do trabalho dentro duma nação leva, primeiramente, à separação do trabalho industrial e comercial do agrícola e, portanto, à separação da cidade e do campo e a um conflito de interesses entre eles. O desenvolvimento posterior conduz à separação das atividades industriais das comerciais. Ao mesmo tempo, através da divisão do trabalho desenvolvem-se mais, dentro dos vários ramos, divisões entre os indivíduos que cooperam em espécies definidas de trabalho. [...]. Os vários estágios de desenvolvimento da divisão do trabalho são, apenas, outras tantas formas diversas de propriedade". 
A doutrina clássica tende a apresentar a liberdade de iniciativa, de acordo com seu ideário liberal, como um dos princípios mais básicos de um modelo capitalista. Balizada nas ideias do liberalismo econômico, um dos desdobramentos da livre iniciativa, tratou-se de doutrina essencial no processo de implantação do Estado liberal, resultando em uma restrição das funções do Estado, limitado apenas às atividades essenciais, como a defesa contra agressões externas, deixando as decisões de natureza econômica serem tomadas pelo próprio mercado, sem as amarras de mecanismos regulatórios estatais ${ }^{12}$.

Essa visão clássica merece ser desmistificada. O conteúdo jurídico do princípio da livre iniciativa, mesmo em seus primórdios históricos, nunca foi o de uma liberdade econômica irrestrita e um Estado absolutamente ausente, não tendo sido essa a maior expressão da livre iniciativa econômica, tendo em vista que esse princípio sempre conviveu com modelos de políticas públicas estabelecidas pelo Estado, conforme enaltece Grau (1997, p. 225):

Vê-se para logo, nestas condições, que no princípio, nem mesmo em sua origem, se consagrava a liberdade absoluta de iniciativa econômica. Vale dizer: a visão de um Estado inteiramente omisso, no liberalismo, em relação à iniciativa econômica privada, é expressão pura e exclusiva de um tipo ideal. Pois medidas de polícia já eram, neste estágio, quando o princípio tinha o sentido de assegurar a defesa dos agentes econômicos contra o Estado e contra as corporações, a eles impostas.

É possível a utilização desse conceito acerca do surgimento do princípio da liberdade de iniciativa econômica, bem como do seu

12 Loucks e Whitney (1981, p. 26) alertam: "O sistema econômico do capitalismo não se distingue pela mera presença física do capital ou pelo uso de métodos de produção de capital relativamente intensivo. A União Soviética seria capitalista por estes critérios. O capitalismo só pode ser definido e diferenciado de outros sistemas econômicos fazendo-se referência a suas instituições. O Capitalismo é um sistema de organização econômica em que os indivíduos, isoladamente ou em grupos, têm a propriedade privada dos fatores de produção e o direito de usar estes recursos econômicos, em geral, da maneira que decidirem". 
papel na difusão do sistema capitalista, para discutir a construção de um novo modelo de ordem econômica e social ${ }^{13}$. É oportuno salientar o comum engano de se pensar na ordem econômica separada da ordem social, como se fossem rivais em eterna tensão. A Constituição deve ser analisada de forma sistemática, superando a visão conflituosa de capital versus trabalho e passando para uma visão humanista de capital e trabalho. Não há uma relação constitucional antagônica ou hierarquizada, e sim harmônica ${ }^{14}$. Deve-se buscar o equilíbrio entre crescimento econômico e propriedade social. No entanto, isso não ocorrerá de forma natural, tornando necessária a presença reguladora do Estado.

Não há dúvidas de que o grande fundamento de um sistema de produção capitalista reside nos ideais de liberdade de iniciativa econômica. Nesse passo, nada mais lógico que, como as crises cíclicas anteriores, esta acarrete na mutação e adaptação do capitalismo a uma nova realidade ${ }^{15}$. Os valores da livre iniciativa devem experimentar o mesmo destino, repensando seu conteúdo jurídico, seus limites, suas realizações, suas contribuições para a realidade social atual e seu destino ${ }^{16}$.

13 Oportuno esclarecer que a própria Constituição vigente tem sua parcela de culpa quanto à aparente dicotomia existente entre as ordens, ao adotar uma sistemática de apartamento entre as ordens econômicas e sociais, diferentemente de constituições anteriores (como as de 1934, 1946, 1967 e 1969). Todavia, esse corte do Constituinte não pode ser visto como uma separação entre as ordens. É essencial a existência de um diálogo entre a livre iniciativa econômica e a efetivação de uma justiça social balizada na valorização do trabalho humano.

14 Dobb (1983, p. 256) afirma: "o homem, como técnico no processo de produção, opõe-se cada vez mais à força de trabalho como mercadoria, que é a base sobre a qual repousa o capitalismo".

15 Sobre os sistemas econômicos e suas mutações oriundas das tensões cíclicas, Carlos Marques Pinho e Davi Benevides Pinho (1984, p. 227) afirmam que "sua contínua evolução se realiza por meio de desequilíbrios provocados por distorções estruturais e busca de adaptações e correções mais ou menos importantes".

16 Para Carlos Marques Pinho e Diva Benevides Pinho (1984, p. 228) "os regimes de economia capitalista, após as duas Grandes Guerras, e a 'Grande Depressão' (1929), vêm apresentando sensíveis modificações internas e externas, que atingem instituições e métodos econômicos [...]. Em todos os países capitalistas o Estado assume, gradativamente, a gestão da atividade econômica, por meio de diferentes mecanismos de intervenção, controle e supervisão; a concorrência é progressivamente regulamentada". 
Por fim, merece crítica a difundida Escola do Neoconstitucionalismo, que, encabeçada por juristas como Luiz Roberto Barroso, Daniel Sarmento, Jane Reis, Ingo Sarlet, entre outros, é responsável por defender a existência de um conteúdo normativo dos princípios constitucionais, além de sua plena aplicabilidade nas relações privadas. Todavia, basta uma análise rápida da atual realidade brasileira para se perceber que os valores elencados pela ordem econômica constitucional ainda não têm se refletido em avanços concretos para a sociedade, não sendo atendidas as necessidades sociais mais básicas de significativa parcela da população, gerando uma estrutura marcada pela desigualdade social.

Diante desse quadro, não deveria haver espaço para dúvidas quanto à natureza programática dos princípios arrolados pelo artigo 170 da Constituição. A simples previsão constitucional de um Estado fundado na valorização do trabalho humano não acarretou na sua efetivação. Para a sua concretização, torna-se essencial a presença do Estado, concedendo-Ihe maior conteúdo jurídico normativo e criando instrumentos que disciplinem o mercado, pautado em um novo modelo, equilibrado com os demais valores da ordem econômica brasileira.

\section{Leituras contemporâneas da fórmula "existência digna e justiça social"}

O conteúdo formador dos princípios jurídico-políticos da ordem econômica de existência digna e justiça social corresponde a uma das maiores conquistas do indivíduo, consagrada pela Constituição de 1988, repudiando sistemas jurídicos que toleram modelos econômicos tendentes a acarretarem na desvalorização da dignidade humana e dos valores sociais do trabalho, núcleo essencial da estrutura ideológica estabelecida pela Lei Magna de 1988.

O constituinte de 1988 tentou alcançar uma renovação dos paradigmas que dominam a globalização econômica, superando o princípio de maximização dos resultados, na busca pelo estabelecimento de uma nova função do país na mundialização da economia, centrada 
em uma maior efetividade da dignidade da pessoa humana. Atribuiu-se ao Estado o dever de combater sistemas pautados no desprezo dos valores constitucionais centrais, devendo estabelecer instrumentos destinados à correção do grande vácuo existente entre as distintas classes sociais que compõem uma sociedade, utilizando a ética e a moral como alicerces desse novo modelo econômico a ser adotado. Essa é a exegese que deve ser aplicada à ordem econômica estabelecida pela Lei Maior de 1988.

A livre iniciativa, conforme prevista pela Constituição, não traz consigo uma garantia contra a participação do Estado no domínio econômico; a única segurança existente é a de que o Estado apenas poderá fazê-lo através de lei formal, ou seja, uma garantia de reserva legal, e somente por meio dela poderão ser estabelecidas fronteiras nítidas para a navegação corporativa entre os valores e princípios assegurados pelo artigo 170 da Constituição Federal.

No entanto, o atual cenário é o de uma sociedade que experimenta elevados níveis de desequilíbrios sociais, os quais vieram ainda mais à tona com a crise global do sistema capitalista, atentando para a existência de um sistema de mercado exclusivamente pautado na obtenção de maiores lucros a todo custo e evidenciando a necessidade latente de uma reorganização das estruturas do direito ao livre mercado, porém, com maior ênfase nos ideais de dignidade humana e justiça social.

A simples busca pelo lucro da atividade econômica não pode ser interpretada como algo ruim, indício da ganância do homem, e sim como algo inerente e inseparável do regime capitalista. O lucro de uma empresa não se encontra necessariamente vinculado à exploração do trabalho humano, sendo possível alcançar uma elevada produtividade conciliável com o aumento de benefícios concedidos ao trabalhador. Entretanto, para que esse quadro, o qual ainda corresponde à exceção, possa se tornar regra e as empresas que adotam essa postura possam se manter competitivas em um sistema capitalista de acirrada concorrência, a presença do Estado regulador se apresenta 
como indispensável, corrigindo as falhas do mercado e eliminando as discrepâncias existentes entre as instituições sociais e a livre iniciativa ${ }^{17}$.

Certamente, corresponde a um dos grandes desafios da atualidade a serem enfrentados pelo Estado brasileiro (e por todos os demais países do globo), que deverá buscar formas para se alcançar o equilíbrio entre a manutenção de uma economia de mercado mundialmente competitiva e o estabelecimento de medidas eficazes o suficiente para garantir a proteção dos mais necessitados, como a repartição equilibrada das riquezas alcançadas pelas corporações oriundas do esforço e das aptidões de seus trabalhadores.

A reformulação desse sistema fomentador da precarização do proletariado somente poderá ser alcançada por meio de um intenso movimento de organização de classes, destinadas a buscar alternativas para o modelo vigente, e não apenas o estabelecimento de críticas a ele. Afinal, para que se possa alcançar uma revolução social, não basta a afirmação daquilo que não mais se quer; é necessário saber pelo que se está lutando, ou seja, por qual modelo o atual deve ser substituído. Deve-se evitar a sedução de discursos vazios pautados em valores igualitário-democráticos radicais, buscando-se uma autorreflexão crítica, procurando alternativas, mas também reconhecendo que não haverá soluções simplórias e óbvias a esse complexo problema.

Nesse sentido, o presente estudo não apenas traz um diagnóstico para o atual sistema econômico e social do Brasil como introduz elementos que contribuem para o desenvolvimento de uma nova visão de ordem econômica, baseada na equidade, igualdade e desenvolvimento, reconstruindo as bases teóricas contemporâneas que continuam a se contrapor a tais valores.

17 No entanto, não poderá ser tolerada uma banalização da atividade normativa do Estado. Este regulamentará apenas quando necessário para a efetivação do processo harmônico aqui defendido, evitando a difusão do fenômeno da juridificação, que, conforme desenvolve Nusdeo (2008, p. 218), corresponde "ao fenômeno da multiplicação das normas legais e regulamentares cuja tendência é a de criar uma babel normativa, dificilmente absorvível pelo mercado, gerando crises de absorção, de má adaptação e de rejeição". 
Certamente, será grande o desafio de implementação de um modelo eficaz de justiça social e existência digna da classe trabalhadora. Essa meta somente poderá ser alcançada através de um processo inicial de reflexão e, posteriormente, de mutação das matrizes clássicas que compõem as relações justrabalhistas atuais ${ }^{18}$. Porém, alerte-se desde já que a reforma proposta não será destinada à implementação de programas socialistas ou anarquistas com posicionamentos mais drásticos defendendo a extinção do capitalismo e sua substituição por uma nova forma de organização social. O que será defendido será um novo modelo de ordem econômica, pautado em um programa regulador do capitalismo.

Nessa toada, introduzem-se, no próximo tópico, alguns exemplos específicos desse necessário processo de reconstrução.

\section{Linhas de mutação de matrizes clássicas das relações jurídico-laborais}

A Consolidação das Leis do Trabalho (CLT) foi desenvolvida ainda na década de 1940, durante a Era Vargas, quando do início do processo de industrialização nacional ${ }^{19}$, com o intuito de regulamentar a relação laboral existente entre o operário da fábrica e o empregador. A longevidade experimentada pelo modelo normativo brasileiro tem cada vez mais sua fragilidade evidenciada. Nos últimos anos, a sociedade nacional experimentou um processo de polimorfismo das relações de emprego com o surgimento de novas espécies de trabalhadores, muitos

18 Como alerta Andrade (2008, p. 215): "esta forma de democratização do trabalho, centrada na cooperação, na solidariedade, na participação, na democracia, só será possível se houver uma inversão de valores, do ponto de vista econômico".

19 Acerca dos avanços tecnológicos e da contradição existente entre o proletariado e a burguesia em um sistema capitalista, Harnecker e Urib (1980, p. 47) defendem que a introdução das máquinas e o aumento da produtividade não acarretaram em uma maior libertação do trabalhador, e sim em uma maior exploração: "com o desenvolvimento do sistema capitalista, o proletariado não só cresce como se vai concentrando nas zonas industriais, o que facilita a sua identificação como classe explorada pelo sistema, submetida ao controle capitalista dentro da fábrica e criadora das riquezas que vão parar nas mãos do capitalista". 
dos quais excluídos da proteção normativa estatal, não lhes sendo assegurado um trabalhado digno, condizente com o patamar mínimo civilizatório dos direitos sociais laborais ${ }^{20}$. Sobre os reflexos das novas tecnologias e sua influência no processo de transformação das relações de trabalho:

Um aspecto dessa manifestação é a diminuição relativa das tarefas manuais de execução. $O$ trabalho se divide em pequenas partes, torna-se cada vez mais complexo e científico; diminuem sensivelmente as tarefas diretamente sujeitas às intervenções humanas. Outro aspecto é que as relações entre os trabalhadores são cada vez mais dependentes, controladas e modificadas periodicamente, o que faz com que a direção do trabalho vá sendo convertida apenas numa lembrança. [...]. As novas técnicas têm eliminado alguns ataques à segurança e à higiene no trabalho, mas, ao mesmo tempo, têm dado lugar ao aparecimento de novas formas de prejudicar os trabalhadores, como o estresse, a monotonia, etc. [...]. A nova tecnologia permite controlar sem chefes as tarefas que os trabalhadores realizam e, sobretudo, nos trabalhos em linhas de montagem. Quer dizer, reduz-se o número de trabalhadores. (RUPRECHT, 1995, p. 253-254)

Frente a essa nova realidade social que se apresenta, surge o questionamento: quem são os trabalhadores protegidos pelo espectro do Direito do Trabalho e quem são aqueles negligenciados, que não possuem pleno acesso aos direitos trabalhistas ${ }^{21}$ ? Não há dúvidas

20 Becker (2010, p.10) afirma: "as leis devem ser modificadas a fim de que os novos problemas sociais e econômicos que proliferam, vertiginosamente, na aceleração da História recebam as respectivas soluções pela criação de novas leis".

21 Analisando a luta de classes no sistema capitalista, Amin (1973, p. 303) elucida a desigualdade social que acarreta na marginalização do proletariado, desenvolvendo-se um quadro de discrepância entre salários e lucros imune a análises estatísticas: "com o desenvolvimento capitalista periférico, aparecem outras categorias de empregos [...]. Algumas constituem a contrapartida da desigualdade crescente na distribuição da renda (empregadas, empregados dos serviços, etc.) outros encobrem um desemprego disfarçado (vendedores ambulantes, por exemplo). Nestas condições, a zona fronteira entre o desemprego e o emprego alarga-se ao ponto de tirar todo o significado às estatísticas oficiais do desemprego". 
acerca do atual declínio da proteção social, que falha em acompanhar o dinamismo das novas morfologias do trabalho, influenciadas pela fragilidade do modelo de relações laborais adotado pelo Brasil, negligenciando o direito ao trabalho digno para diversas espécies de trabalhadores.

A operacionalização de um direito do trabalho harmônico com os valores fundamentais assegurados pela Constituição corresponde ao grande desafio da ciência justrabalhista e só poderá ser alcançada por meio da mudança de seus paradigmas clássicos, desenvolvendo-se um novo modelo, a possibilitar uma correção das desigualdades sociais existentes nas relações laborais não regulamentadas, mostrando-se essencial uma intervenção estatal que promova a igualdade não por uma concepção de generalidade ${ }^{22}$, mas respeitando as peculiaridades inerentes a cada forma de trabalho, reequilibrando o sistema de proteção social ${ }^{23}$.

\subsection{Reconhecimento dos direitos de cidadania do trabalhador}

Conforme a clássica divisão de direitos fundamentais em gerações ou dimensões, consagraram-se como direitos de primeira dimensão

22 Sobre o necessário processo de revisão dogmática do Direito do Trabalho e as ameaças oriundas do sistema econômico globalizado, Menezes (2004, p. 249) assim se pronuncia: "A construção dogmática do Direito do Trabalho se escora numa releitura do princípio da igualdade, passando a admitir o tratamento desigual, desde que haja razão suficiente para tanto. Trata-se de uma visão de igualdade material, e não exclusivamente formal. Esse, portanto, é o cerne da legislação de inspiração social que protege o trabalho. Ao longo de sua existência, porém, as ideias que fundamentaram o direito do trabalho sempre foram questionadas pela vertente filosófica que buscava conferir caráter absoluto ao direito de propriedade e à liberdade de contratar. $\mathrm{A}$ globalização proporcionou o resgate dessa concepção, antes relegada a um conservadorismo ultrapassado. Agora o liberalismo aparece renovado e pronto para alcançar a sua ofensiva contra o direito do trabalho, que considera incômodo e subversivo".

23 Nesse sentido, Franceschet (2012, p. 324) enaltece que "impõe-se, portanto, o desafio de aplicar mecanismo de proteção justrabalhista. Em um primeiro momento, deve-se identificar qual o estuário mínimo comum de direitos primordiais ao exercício digno da atividade produtiva de todas as pessoas que trabalham. Ato contínuo, importa verificar quais são as peculiaridades inerentes a cada um dos ramos de atividades prestacionais, hoje excluídas da tutela trabalhista e estudar o modo como o ordenamento jurídico pode intervir para regulá-la adequadamente, de modo a favorecer a sua concretização". 
os direitos de cidadania; e como direitos de segunda dimensão, os econômicos, sociais e trabalhistas. Porém, no atual processo de efetivação dos direitos fundamentais, começam a despertar novas ideias quanto à amplitude de aplicação dos direitos de cidadania, trazendo-os para um novo contexto no âmbito das relações do trabalhador com a empresa.

Como consequência desse processo de "cidadania da empresa", haveria a formação de uma nova figura, a do "cidadão-trabalhador", detentor de direitos laborais não tradicionais ${ }^{24}$, por se tratarem de valores de primeira dimensão, como: direito à informação (aplicável desde hipóteses de dispensa sem justa causa até o direito de conhecer a real situação econômico-financeira da empresa); direitos de personalidade (como o de ter asseguradas sua privacidade e dignidade frente às novas tecnologias utilizadas para maximizar o poder fiscalizatório do empregador ${ }^{25}$ ); direito à ampla defesa e ao contraditório (em hipóteses de dispensa por justa causa, em que se alega falta grave por parte do trabalhador $\left.{ }^{26}\right)$, entre outros.

No Direito comparado, observa-se que esse cenário de expansionismo do Direito do Trabalho já se encontra assegurado, por

24 Canotilho (2011, p. 385) expõe a necessidade de um processo evolutivo das teorias tradicionais dos direitos sociais. Para o jurista português, "se o capitalismo mercantil e a luta pela emancipação da sociedade burguesa são inseparáveis da conscientização dos direitos do homem, de feição individualista, a luta das classes trabalhadoras e as teorias socialistas [...] põe em relevo a unidimensionalização dos direitos do homem 'egoísta' e a necessidade de completar (ou substituir) os tradicionais direitos do cidadão burguês pelos direitos do 'homem total', o que só seria possível numa nova sociedade."

25 Berger (1992, p. 90) elucida: "A moderna tecnologia assegura isto pela habilidade imensamente crescente dos seres humanos em controlar seu meio-ambiente, minimizando, assim, aqueles aspectos da vida que foram antes experimentados e reconhecidos como um destino inalterável. O paradoxo é que esta moderna tecnologia também fornece os meios pelos quais as instituições poderosas podem controlar a vida dos indivíduos. Assim, o Estado totalitário se torna possível pela moderna tecnologia. O grande drama da modernidade é esta tensão dinâmica entre a liberação e a reescravização".

26 Para Martins (2008, p. 204): "Seria possível também criar na empresa uma espécie de comissão de fábrica de modo a verificar as causas da dispensa do trabalhador, assegurando-lhe a oportunidade de defesa àquele. O próprio departamento de pessoal da empresa poderia ouvir o empregado antes de ser dispensado, para verificar o que o obreiro tem a dizer". 
exemplo, pelo Código de Trabalho Português de 200927. Todavia, no Brasil, ainda não há legislações trabalhistas positivando a aplicação dos direitos de cidadania no âmbito do contrato de trabalho ${ }^{28}$. Logo, frente à natureza aberta e programática de tais princípios, sua eficácia continua sendo inexpressiva, oriunda de decisões judiciais esparsas, insuficientes para acarretar em uma real evolução social da classe proletária. Mostra-se necessária a realização de maiores estudos que proporcionem o desenvolvimento de teorias condizentes com esse processo de polimorfismo e que melhor adéquem tais direitos na esfera das relações laborais.

5.2 Reflexos do capitalismo contemporâneo: os fenômenos da terceirização e do dumping social

O sistema global capitalista possui como grande característica seu dinamismo, tratando-se de um modelo econômico e social detentor de elevada capacidade de adaptação e transformação de suas bases estruturais, fazendo com que possa preservar harmonicamente o núcleo de suas ideologias, mesmo frente às crises cíclicas por ele enfrentadas. No entanto, o modelo contemporâneo de capitalismo tem sido marcado por consequências injustas para a classe operária, ao acarretar em uma mitigação dos valores sociais e um declínio da democracia, estabelecendo um "Estado de ilusão democrática".

Entre as transformações radicais das relações justrabalhistas oriundas do modelo de capitalismo ultraliberal ocidental contemporâneo, tem-se presenciado os fenômenos intitulados de "flexibilização dos direitos trabalhistas", que, sob o fundamento de tornarem as empresas brasileiras mais competitivas em um sistema de mercado globalizado,

\footnotetext{
27 O direito à informação dos trabalhadores repousa no artigo 353 do citado Código. A ampla defesa e o contraditório se encontram previstos no artigo 353 , I. Os direitos de personalidade são elencados em diversos dispositivos do Código.

28 Almeida (2012, p. 296) esclarece que "embora no Brasil os direitos fundamentais inespecíficos dos trabalhadores não tenham ainda, na maioria das hipóteses, uma regulamentação infraconstitucional adequada, [...] são garantidos em razão da eficácia dos direitos constitucionais fundamentais".
} 
estabelecem um desequilíbrio nas relações laborais, com um retrocesso de direitos previamente alcançados, acarretando em um aumento dos lucros a partir da redução de custos com mão de obra e gerando um sistema de precarização e sacrifício de direitos sociais.

Como exemplos de tais dinâmicas corporativas predatórias, merecem destaque as mutações denominadas de dumping social e terceirização.

O dumping social ${ }^{29}$ tem como característica primordial a redução de custos econômicos em detrimento dos direitos sociais, burlando os limites normativos da proteção laboral e resultando em inevitáveis agressões aos direitos sociais trabalhistas. Trata-se de um fenômeno desconhecido para o ordenamento jurídico brasileiro, não possuindo qualquer chancela do Estado, sendo, portanto, ainda escassos os estudos jurídicos destinados à investigação do tema. Isso dificulta alcançar um diagnóstico preciso acerca dessa patologia, obstaculizando o desenvolvimento de instrumentos eficazes o suficiente para combater tais agressões sociais.

Quanto à terceirização, ela tem suas origens vinculadas à Itália e ao Japão e é oriunda da crise global do capitalismo na década de 1970, sendo a exteriorização de um novo método de produção, marcando a "era da especialização", quando as empresas cessam a concentração de suas forças na realização de todas as etapas de produção, repassando às demais, especializadas, a execução de suas atividades periféricas, concentrando-se, então, apenas em suas atividades principais. Assim, estabelece-se uma nova dinâmica de produção econômica, abandonando o método de organização vertical desenvolvido por

29 Pinto (2011, p. 141) aponta de forma precisa os reflexos malignos do fenômeno do dumping social: "O dumping atropela preferencialmente o Direito em três de seus mais importantes segmentos na dinâmica social moderna: civil, na medida em que invade a área das obrigações (contratos) e do direito de empresa; trabalhista, na medida em manipula malignamente a relação individual de emprego, e consumerista, na medida em que tumultua as relações de consumo". 
Henry Ford e Friedrich Taylor e aderindo a uma forma de organização horizontal ${ }^{30}$.

Apesar da ampla utilização dessa forma de redução de gastos empresariais, a realidade é que a terceirização ainda corresponde a um fenômeno não regulado pelo sistema jurídico pátrio ${ }^{31}$, sendo utilizada de forma abusiva, camuflando verdadeiras relações de emprego e originando uma nova espécie de intermediação de mão de obra fenômeno vedado pelas normas trabalhistas justamente por acarretar na fragilização das relações laborais e precarização dos direitos sociais ${ }^{32}$.

Diante desse quadro, é essencial a queda do muro existente entre capital e trabalho, reestruturando as bases do vigente sistema corporativista, marcado pelo desequilíbrio e pela inexistência de harmonia entre a livre iniciativa empresarial e a valorização do trabalho humano ${ }^{33}$, alcançando uma evolução da ciência juslaboral, superando as desigualdades econômicas e sociais por meio de uma reformulação hermenêutica aplicável aos princípios constitucionais que regem a ordem econômica vigente, desenvolvendo-se uma teoria de justiça social em consonância com os valores de um Estado Democrático de Direito.

30 Pompeu e Almeida (2009, p. 8941) esclarecem que foi "nos primórdios da década de 1970 que essa mentalidade começou a ser revista. Em virtude da crise do capitalismo mundial, países como Itália e Japão começaram a desenvolver formas distintas de obter acúmulo de capital. Assim, surge um novo método de acumulação de capital distinto dos que vinham sendo exercidos até aquele momento, em que a produção migrava de um método de organização vertical para uma nova organização horizontal, por meio de diferentes empresas atuando como prestadoras de serviços específicos".

31 Até o presente momento, todo o instituto é regulado apenas por intermédio da Súmula $\mathrm{n}^{\circ}$. 331 , do TST.

32 Martins (2001, p. 40) defende que a terceirização no âmbito empresarial "só deveria haver transferência para terceiros de atividades subsidiárias, atividades-meio da empresa [...]. Com a terceirização da atividade-fim do empreendimento, a empresa não estaria prestando serviços, mas fazendo arrendamento do negócio".

33 Conforme enaltece Antunes (1995, p. 130), "a emancipação do trabalho não se confunde com tempo livre ou liberado, mas sim com uma nova forma de trabalho, que se realize, em sua integralidade, a omnilateralidade humana, o livre desenvolvimento das individualidades, a plena realização e emancipação do ser social." 


\section{Conclusão}

Dada a atual crise do sistema capitalista e a disseminação epidêmica de movimentos sociais globais que reivindicam mudanças nos princípios estruturantes dos Estados capitalistas, é essencial buscar uma precisa delimitação de como esse novo modelo de capitalismo deverá se equilibrar com os direitos sociais dos trabalhadores, estabelecendo uma relação econômico-social entre esses agentes de coordenação que não seja mais de exclusão.

Conforme exposto no presente estudo, entendemos que esse objetivo apenas poderá ser alcançado por intermédio do estabelecimento de futuras reflexões que estejam direcionadas aos seguintes desafios:

I) Investigar a relação existente entre os sistemas econômicos centralizados na doutrina neoliberal e o abalo às estruturas constitucionais sociais que deveriam nortear as relações empresariais, demonstrando a necessidade de uma mutação da conjuntura econômica.

II) Refletir acerca do direito à liberdade de iniciativa em sistemas capitalistas e como alcançar uma conexão desse regime com os valores estruturantes de uma democracia, rompendo-se com a visão predominante de que os princípios da ordem econômica correspondem a uma utopia e são possuidores de um conteúdo esvaziado de qualquer sentido mais amplo.

III) Diagnosticar as causas que acarretam na tensão existente entre a livre iniciativa privada e a justiça social, buscando-se formas de balancear os primados da livre iniciativa e os valores de um trabalho humano digno, repensando as matizes clássicas que regem as relações jurídico-laborais.

IV) Perquirir sobre o conteúdo jurídico do princípio da livre iniciativa e qual a correlação entre a ampliação desse princípio e o atual cenário de elevados níveis de desequilíbrios sociais, evidenciando a necessidade de uma reorganização das estruturas do direito ao livre mercado, dando-se maior ênfase aos ideais de dignidade humana e justiça social. 
V) Demonstrar que, com o declínio do capitalismo, há a necessidade de uma transição de sistemas e que o Estado assuma um papel mais ativo, balanceando avanços econômicos e progresso social, assegurando a efetividade do núcleo essencial da estrutura ideológica estabelecida pela Constituição de 1988.

\section{Referências}

ALMEIDA, Renato Rua de. Direitos laborais inespecíficos dos trabalhadores. Revista LTr: Legislação do Trabalho, São Paulo, v. 76, n. 3, p. 295-296, mar. 2012.

AMIN, Samir. O desenvolvimento desigual: ensaios sobre as formações sociais do capitalismo periférico. Tradução Francisco Rego Chaves Fernandes. Rio de Janeiro: Forense Universitária, 1973.

ANDRADE, Everaldo Gaspar Lopes. Princípios de direito do trabalho: fundamentos teórico-filosóficos. São Paulo: LTr, 2008.

ANTUNES, Ricardo. Adeus ao trabalho? Ensaio sobre a metamorfose e a centralidade do mundo do trabalho. 3. ed. São Paulo: Cortez, 1995.

BARAN, Paul A.; SWEEZY, Paul M. Capitalismo monopolista: ensaios sobre a ordem econômica e social americana. Tradução Waltensir Dutra. Rio de Janeiro: Zahar, 1966.

BECKER, Alfredo Augusto. Teoria geral do direito tributário. 5. ed. São Paulo: Noeses, 2010.

CANOTILHO, J.J. Gomes. Direito constitucional e teoria da constituição. 7. ed. Coimbra: Almedina, 2011.

CARDOSO, Fernando Henrique. A democracia necessária. Campinas, SP: Papirus, 1985.

CASTELLS, Manuel. A era da informação: economia, sociedade e cultura. São Paulo: Paz e Terra, 2000. v. 2.

DOBB, Maurice Herbet. A evolução do capitalismo. Tradução Manuel do Rêgo Braga. São Paulo: Abril Cultural, 1983. 
FRANCESCHET, Patrícia Rebouças. O expansionismo do direito do trabalho no Brasil: possibilidades concretas para a adequada inclusão das diferentes morfologias do trabalho pela via legislativa. Revista LTr: Legislação do Trabalho, São Paulo, v. 76, n. 3, p. 322-327, mar. 2012. GRAU, Eros Roberto. A ordem econômica na constituição de 1988. 3. ed. São Paulo: Malheiros, 1997.

HABERMAS, Juergen. A crise de legitimação no capitalismo tardio. Rio de Janeiro: Tempo Brasileiro, 1980.

HARNECKER, Marta; URIBE, Gabriela. Capitalismo e socialismo. São Paulo: Global, 1980.

JAMESON, Frederic. A cultura do dinheiro. Petrópolis: Vozes, 2001.

KELLER, Arno Arnoldo. O descumprimento dos direitos sociais: razões políticas, econômicas e jurídicas. São Paulo: LTr, 2001.

LOUCKS, William N.; WHITNEY, William G. Sistemas econômicos comparados. Tradução José Ricardo Brandão Azevedo. Rio de Janeiro: Livros Técnicos e Científicos, 1981.

MAGANO, Octávio Bueno. Política do trabalho. São Paulo: LTr, 1995. v. II.

MARTINS, Sergio Pinto. Direitos fundamentais trabalhistas. São Paulo: Atlas, 2008.

MARTINS, Sergio Pinto. A terceirização e o direito do trabalho. São Paulo: Atlas, 2001.

MARX, Karl. Formações econômicas pré-capitalistas. Tradução João Maia. 7. ed. São Paulo: Paz e Terra, 2006.

MENEZES, Mauro de Azevedo. Constituição e reforma trabalhista no Brasil: interpretação na perspectiva dos direitos fundamentais. São Paulo: Ltr, 2004.

MORIN, Edgar. Para sair do Século XX. Rio de Janeiro: Nova Fronteira, 1986. 
NUSDEO, Fábio. Curso de economia. 5. ed. São Paulo: Revista dos Tribunais, 2008.

PESCHANSKI, João Alexandre. Os "ocupas" e a desigualdade econômica. In: HARVEY, David et al. Occupy. São Paulo: Boitempo, 2012. p. 27-30.

PINHO, Carlos Marques; PINHO, Diva Benevides. Sistemas econômicos comparados. São Paulo: Saraiva, 1984.

PINTO, José Augusto Rodrigues. Dumping social ou delinquência patronal na relação de emprego? Revista TST, Brasília, DF, v. 77, n. 3, p.136-151, jul./set. 2011.

POMPEU, Gina Vidal Marcílio; ALMEIDA, Saulo Nunes de Carvalho. A terceirização e a precarização da dignidade do trabalhador: perspectivas. In: ENCONTRO NACIONAL DO CONPEDI, 19., 2010, Fortaleza. Anais... Fortaleza, 2010. Disponível em:<http://www.conpedi.org.br/ manaus/arquivos/anais/fortaleza/3542.pdf>. Acesso em: 22 jun. 2013.

RUPRECHT, Alfredo J. Relações coletivas de trabalho. São Paulo: LTr, 1995.

SARLET, Ingo Wolfgang et al. Curso de direito constitucional. 2. ed. São Paulo: Revista dos Tribunais, 2012.

SILVA, Américo Luís Martins. A ordem constitucional econômica. 2. ed. São Paulo: Forense, 2003.

SMITH, Adam. Uma investigação sobre a natureza e causa da riqueza das nações. Tradução Noberto de Paula Lima. São Paulo: Hermus, 2001.

Recebido em: 00/11/13

Aprovado em: 00/12/13 